\title{
Endoscopic third ventriculostomy
}

\author{
Viroj Wiwanitkit
}

Received: 7 April 2010 /Accepted: 30 April 2010 /Published online: 12 May 2010

(C) Springer-Verlag 2010

\section{Dear Editor}

Editor, I read the recent publication on endoscopic third ventriculostomy (EVT) by Marton et al. with a great interest [1]. Marton et al. concluded that "ETV secondary to shunt malfunction in pediatric patients has a success rate of $64 \%$. As it is a safe and rapid treatment option even in emergency conditions, it is worth performing this procedure in previously shunted children [1]." Indeed, a similar report on the success rate of ETV was recently reported by O'Brien et al. [2]. I have some additional concerns on this report. As a retrospective report, the result might be deviated due to uncontrolled bias. The success rate in this work is not high and this might be a problem for selecting ETV as the first choice for management of the patients, especially in emergency condition. It is also questionable whether EVT is a rapid option. There should be supportive evidence to support this conclusion. Also, there should be more information on the cost effectiveness of EVT compared to other options.

\section{References}

1. Marton E, Feletti A, Basaldella L, Longatti P (2010) Endoscopic third ventriculostomy in previously shunted children: a retrospective study. Childs Nerv Syst. doi:10.1007/s00381-010-1130-1

2. O'Brien DF, Javadpour M, Collins DR, Spennato P, Mallucci CL (2005) Endoscopic third ventriculostomy: an outcome analysis of primary cases and procedures performed after ventriculoperitoneal shunt malfunction. J Neurosurg 103(5 Suppl):393-400

V. Wiwanitkit $(\bowtie)$ 